\title{
PRODUKTIVITAS TENAGA KERJA DENGAN METODE WORK SAMPLING PROYEK PERUMAHAN DI KOTA PEKANBARU
}

\author{
Gusneli Yanti \\ Program Studi Teknik Sipil Universitas Lancang Kuning \\ Jalan Yos Sudarso Km. 8 Rumbai Pekanbaru \\ E-mail : gusneli@unilak.ac.id
}

\begin{abstract}
Abstrak
Produktivitas tenaga kerja merupakan salah satu unsur utama dalam menentukan keberhasilan pelaksanaan suatu proyek konstruksi, tapi sering kali penggunaan tenaga kerja yang tidak efektif. Work sampling adalah salah satu metode pendekatan yang bisa digunakan untuk mengukur produktivitas dengan cukup mudah. Tujuan dari penelitian ini adalah untuk menganalisa produktivitas pekerja tukang batu pada pekerjaan pasangan dinding batu bata serta plesteran pada proyek perumahan di Kota Pekanbaru dengan metode work sampling. Besarnya produktivitas dari tenaga kerja dapat dilihat dari hasil perhitungan waktu baku. Waktu baku adalah waktu yang diselesaikan oleh tenaga kerja dalam melaksanakan pekerjaanya pada kondisi standar. Ukuran produktivitas yang didapat dari analisa ini adalah Labor Utilization Rate (LUR). Hasil analisa work sampling menunjukkan bahwa secara keseluruhan LUR hasil pengamatan dan analisis pada Proyek Perumahan di Kota Pekanbaru adalah sebesar 72,37\% dengan proporsi untuk kegiatan effective $66,03 \%$, essential contributory sebesar $25,79 \%$ dan ineffective sebesar $8,18 \%$.
\end{abstract}

Kata Kunci : $\quad$ Labor Utilization Rate, Produktivitas, Work Sampling

\begin{abstract}
Labor productivity is one of the key elements in determining the successful implementation of a construction project, but often the use of ineffective labor. Work sampling is one approach method that can be used to measure productivity quite easily. The purpose of this study is to analyze the productivity of masonry workers on the work of wall pairs of bricks and plastering on Housing Project in Pekanbaru City with work sampling method. The amount of labor productivity can be seen from the calculation of standard time. Standard time is the time that is completed by the workforce in carrying out its work under standard conditions. The measure of productivity gained from this analysis is the labor utilization rate (LUR). The result of work sampling analysis shows that overall LUR result of observation and analysis on Housing Project in Pekanbaru City is $72,37 \%$ with proportion for effective activity 66,03\%, essential contributory equal to $25,79 \%$ and ineffective equal to $8,18 \%$.
\end{abstract}

Keywords : Labor Utilization Rate, Productivity, Work Sampling 


\section{A. PENDAHULUAN}

Pembangunan proyek di masa sekarang ini begitu meningkat, namun sebaliknya juga terbatasnya kebutuhan sumber daya berkualitas yang tersedia. Menghadapi keadaan tersebut, dalam pelaksanaan suatu pekerjaan atau kegiatan dalam suatu proyek langkah yang perlu ditempuh yaitu mempertajam prioritas dan mengusahakan agar efisien dan efektif dalam pengolahan sumber daya agar dicapai hasil yang maksimal. Sumber daya yang dimaksud berupa sumber daya manusia, material dan peralatan.

Sumber daya sering kali terbatas dan tidak sesuai harapan. Sehingga dalam pelaksanaan pekerjaan tidak bisa diselesaikan sesuai dengan waktu yang telah ditetapkan sebelumnya. Keterlambatan pelaksanaan pekerjaan ini dapat disebabkan oleh berbagai macam faktor. Salah satu faktor yang sangat penting adalah tenaga kerja. Apabila tenaga kerja yang digunakan kurang terampil ataupun tidak maksimal dalam pekerjaannya, maka hasil kerja yang diperoleh kualitasnya kurang baik dan produktivitasnya rendah.

Produktivitas tenaga kerja bukan merupakan sesuatu yang konstan. Produktivitas tenaga kerja dapat berubah-ubah dari waktu ke waktu. Naik atau turunnya produktivitas tukang sebagai tenaga kerja lapangan harus dicermati agar dapat ditentukan sistem kerja yang sesuai dan jumlah tenaga kerja yang dibutuhkan sehingga dapat menghasilkan produk yang sesuai dengan harapan.

Khusus untuk pekerjaan pemasangan batu bata dinding bangunan, dilakukan oleh tukang batu dan dibantu oleh kenek. Biasanya, seorang tukang batu dibantu oleh seorang kenek dalam melakukan pekerjaannya. Terkadang, dua orang tukang batu dibantu oleh seorang kenek dalam pekerjaan memasang batu bata dinding bangunan. Sudah tentu komposisi yang berbeda akan menghasilkan luasan pekerjaan yang berbeda pula, dengan kata lain produktivitas pasangan tenaga kerja tersebut berbeda-beda.

Ada banyak metode yang bisa digunakan untuk mengukur produktivitas pekerja. Namun pengukuran ini sulit untuk dilakukan secara akurat. Oleh karena itu, metodemetode pendekatan biasanya dilakukan untuk mengukur produktivitas pekerja antara lain metode Work Sampling.

Penelitian ini bertujuan untuk menganalisa produktivitas pekerja dengan metode work sampling dan ukuran produktivitas yang didapat dari analisa ini adalah labor utilization rate (LUR).

\section{B. TINJAUAN PUSTAKA}

\section{Proyek}

Proyek merupakan suatu proses sumber daya dan adanya dana tertentu secara terorganisasi untuk menjadi hasil pembangunan yang mantap sesuai dengan tujuan dan harapan-harapan awal dengan menggunakan anggaran dana dari proyek tersebut, sehingga menjadi sumber daya yang tersedia dalam jangka waktu tertentu yang sesuai dengan fungsinya (Dipohusodo I., 1996).

Menurut Weiss J., (1992) suatu kegiatan bisa dikategorikan sebagai proyek kontruksi jika memenuhi beberapa ciri sebagai berikut :

a. Memiliki awal dan akhir kegiatan dari suatu rangkaian kegiatan

b. Jangka waktu kegiatan terbatas

c. Rangkaian kegiatan yang terjadi tidak berulang sehingga menghasilkan produk yang unik 
d. Memiliki tujuan yang spesifik, produk akhir atau hasil kerja akhir

\section{Produktivitas}

Menurut Ervianto W.I., (2005), produktivitas didefinisikan sebagai rasio antara output dengan input, atau rasio antara hasil produktivitas dengan total sumber daya yang digunakan. Dalam proyek konstruksi, rasio produktivitas adalah nilai yang diukur selama proses konstruksi, dapat dipisahkan menjadi biaya tukang, material dan alat.

Pengukuran produktivitas tenaga kerja menurut sistem pemasukan fisik perorangan atau per orang atau per jam kerja orang diterima secara luas, namun dari sudut pandang pengawasan harian, pengukuran-pengukuran tersebut pada umumnya tidak memuaskan karena adanya variasi dalam jumlah yang diperlukan untuk memproduksi satu unit produk yang berbeda. Sinungan M., (2008) lebih menyetujui metode pengukuran waktu tenaga kerja (jam, hari, bulan, tahun).

Jam-orang bagi perusahaan yang sudah sering menangani proyek atau kegiatan jasa konstruksi, umumnya memiliki data atau informasi tentang perkiraannya. Bila hal tersebut belum tersedia atau belum diperhitungkan, dapat digunakan angka hasil analisis dan perbandingan pekerjaan sejenis yang pernah dilaksanakan. Untuk membuat perkiraan jumlah tenaga kerja perbulan dari jumlah jam-orang yang diketahui, perlu diperhitungkan berapa lama jam kerja selama seminggu dan efektivitasnya. Efektivitas telah memperhitungkan hari libur, cuti, dan lain-lain.

Produktivitas tenaga kerja secara individu disebut produktivitas parsial yang merupakan satu diantara jenis masukan dalam proses produksi. Jelasnya, produktivitas tenaga kerja adalah sekian unit atau sekian rupiah barang (yang dihasilkan) per satu orang tenaga kerja per satuan waktu (per jam, per hari, per bulan atau per tahun) (Simanjuntak P.J., 2005). Dengan demikian, pada pekerjaan konstruksi seperti pasangan batu bata dinding, plesteran, pasangan keramik dapat diukur dengan satuan luas sebagai output yang dihasilkan oleh tenaga kerja. Nilai input yang diperkirakan dapat berupa jam kerja untuk menghasilkan luasan kerja (output) yang dimaksud.

Greenberg L., mendefinisikan produktivitas sebagai perbandingan antara total pengeluaran pada waktu tertentu dibagi total pemasukan selama periode tersebut. Dengan demikian produktivitas dapat dirumuskan sebagai berikut :

$$
\mathrm{P} \quad=\frac{\mathrm{O}}{\mathrm{I}}
$$

Dengan :

$$
\begin{aligned}
\mathrm{P} & =\text { Produktivitas }\left(\mathrm{m}^{2} / \text { menit }\right) \\
\mathrm{O} & =\text { Output }\left(\mathrm{m}^{2}\right) \\
\mathrm{I} & =\operatorname{Input}(\text { menit })
\end{aligned}
$$

Ukuran output (O) dapat dinyatakan antara lain dalam bentuk: a. Jumlah satuan fisik produk atau jasa

b. Nilai rupiah produk/jasa

Ukuran input (I) dapat dinyatakan antara lain dalam bentuk:

a. Jumlah waktu

b. Jumlah tenaga kerja

c. Jumlah biaya tenaga kerja

d. Jumlah material

\section{Metode Work Sampling}

Pengukuran produktivitas tenaga kerja di konstruksi dapat dilakukan dengan metode-metode pendekatan, yang salah satunya adalah metode work sampling. Work sampling secara umum 
dapat dikatakan sebagai suatu teknik dimana banyak dilakukan pengamatanpengamatan instan dalam periode waktu dari suatu kelompok pekerja, mesin atau proses.

Work sampling memiliki prinsipprinsip tertentu dalam menjalankannya, yaitu :

a. Pengamat harus dapat dengan cepat mengidentifikasikan individu dari sample untuk dapat digolongkan

b. Sample yang diamati tidak boleh kurang dari 384 pengamatan

c. Sample terkumpul dari bermacammacam bagian siklus tenaga kerja untuk memastikan setiap unit mempunyai kesempatan yang sama untuk diamati

d. Dikelompok besar manapun, sebuah sample diambil secara acak yang akan mewakili sebagian atau seluruh karakteristik dari kelompok tersebut. Dengan kata lain, sebuah sample tidak boleh menunjukkan kondisi atau situasi khusus yang akan memberikan dampak bagi yang akan diamati

e. Untuk menghindari prasangka, pencatatan harus dilakukan secara cepat tanpa ragu-ragu seperti apa yang dilihat pertama kali

Dalam penelitian ini metode yang dipakai adalah productivity rating, dimana kegiatan seorang pekerja digolongkan menjadi 3 (tiga), yaitu: effective, essential contributory, dan ineffective.

Pengertian ketiga jenis kegiatan ini adalah sebagai berikut :

a. Effective work adalah pekerjaan dimana kegiatan pekerja berkaitan langsung dengan proses konstruksi yang berperan langsung terhadap hasil akhir. Contohnya adalah pekerjaan memasang bata, memplester dinding, dan lain-lain b. Essential contributory work adalah kegiatan yang tidak berpengaruh langsung terhadap hasil akhir, tetapi pada umumnya dibutuhkan dalam menjalankan suatu operasi. Contohnya adalah membaca gambar, membersihkan tempat kerja, membawa material, dan lain lain

c. Ineffective work adalah kegiatan pekerja yang menganggur atau melakukan sesuatu yang tidak berkaitan langsung dengan pekerjaan yang sedang dilakukan. Contohnya adalah pekerja yang hanya berjalanjalan saja tanpa membawa apa-apa, melakukan pekerjaan yang tidak sesuai prosedur, mengobrol dll

Pengamatan di lapangan dilakukan dengan cara sebagai berikut :

a. Pengamat harus melengkapi diri, minimum dengan kertas dan alat tulis

b. Pengamat mengelilingi lapangan, lalu mencatat pekerja yang ditemui dan menggolongkannya ke dalam salah satu jenis kegiatan (effective, essential contributory, atau ineffective work)

c. Pengamatan dilakukan dengan mengikuti prinsip-prinsip work sampling yang telah dijabarkan di atas.

Setelah pengamatan selesai dilakukan, dilakukan perhitungan jumlah pekerja di masing-masing jenis kegiatan. Untuk menghitung berapa besar tingkat keefektifan (produktifitas) pekerja digunakan pendekatan Labor Utilization Rate (LUR).

LUR dapat digunakan untuk mengetahui seberapa efektif (produktif) pekerja pada suatu proyek, tetapi tidak dapat menjelaskan mengapa nilainya rendah atau tinggi. Dengan kata lain LUR tidak dapat menunjukkan faktorfaktor yang menyebabkan rendahnya atau tingginya produktivitas pekerja 


\section{DATA DAN ANALISA DATA}

Penelitian ini dilaksanakan di Proyek Perumahan Green Serasi Residence di Kota Pekanbaru.

Pengamatan dilakukan selama 5 (lima) hari dan waktu pekerjaan sesuai jam kerja pada proyek yaitu mulai jam 08.00 WIB sampai jam 17.00 WIB.

Untuk studi work sampling, penelitian ini mengikuti prinsip-prinsip seperti telah dipaparkan di atas. Jenis pekerjaan yang diamati adalah kegiatan atau pekerjaan pasangan tukang batu. Semua pekerjaan ini kemudian digolongkan menjadi tiga jenis kegiatan: effective, contributory, atau ineffective.

Nilai LUR (Labor Utilization Rate) dihitung dengan formula berikut :

LUR $=\frac{\text { Effective }+1 / 4 \text { Essential Contributo ry }}{\text { Total Pengamatan }}$

Effective dan essential contributory adalah jumlah pekerja yang melakukan effective work dan essential contributory work secara berturut-turut, dan total pengamatan adalah jumlah total pekerja dari ketiga jenis kegiatan (effective + essential contributory + ineffective works).

\section{HASIL DAN PEMBAHASAN}

Setelah dilakukan pengamatan di lapangan diperoleh hasil dari pengamatan dan pencatatan aktivitas tenaga kerja di lapangan ketika melakukan pekerjaan pemasangan dinding batu bata selama 5 (lima) hari untuk 5 (lima) orang tenaga kerja.

\section{Hasil Perhitungan LUR}

Perhitungan LUR untuk pekerjaan pembesian dilakukan dengan melakukan rekapitulasi data secara keseluruhan terlebih dahulu. Jumlah pekerjaan effective, contributory, ineffective, dijumlahkan menurut klasifikasinya. Kemudian total nilai setiap perkerjaan digunakan untuk perhitungan LUR. LUR untuk pekerjaan pemasangan dinding batu bata adalah $72,37 \%$, hasil dan proporsi setiap kegiatan dalam pekerjaan ini dalam Tabel 1.

Dari hasil work sampling dari pekerjaan pemasangan dinding batu bata secara keseluruhan pada proyek perumahan diperoleh persentase pekerjaan effective tercatat sebesar $66 \%$ sedangkan essential contributory sebesar $26 \%$ dan ineffective sebesar $8 \%$.

\section{Nilai LUR Berdasarkan Waktu Pengamatan}

Hasil pengamatan dan hitungan berdasarkan waktu secara garis besar dibagi menjadi 2 (dua) bagian yaitu pagi dari pukul 08.00 - 12.00 dan kemudian sesi siang dari pukul 14.00 - 17.00, diperoleh hasil seperti tabel 2 dan tabel 3.

Tabel 1. Hasil Analisis Work Sampling Pada Proyek Perumahan

\begin{tabular}{lcc|c|c}
\hline \multicolumn{1}{c}{ Jenis } & $\begin{array}{c}\text { Jumlah } \\
\text { Kegiatan }\end{array}$ & $\begin{array}{c}\text { Proporsi } \\
(\boldsymbol{\%})\end{array}$ & $\begin{array}{c}\text { Total } \\
(\boldsymbol{\%})\end{array}$ & $\begin{array}{c}\text { LUR } \\
(\boldsymbol{\%})\end{array}$ \\
\hline Effective & 841 & 66,03 & 66,03 & \\
Essential Contributory & 327 & 25,79 & 91,82 & \\
Ineffec-tive & 103 & 8,18 & 100 & $\mathbf{7 2 , 3 7}$ \\
Total & 1275 & 100 & & \\
\hline
\end{tabular}




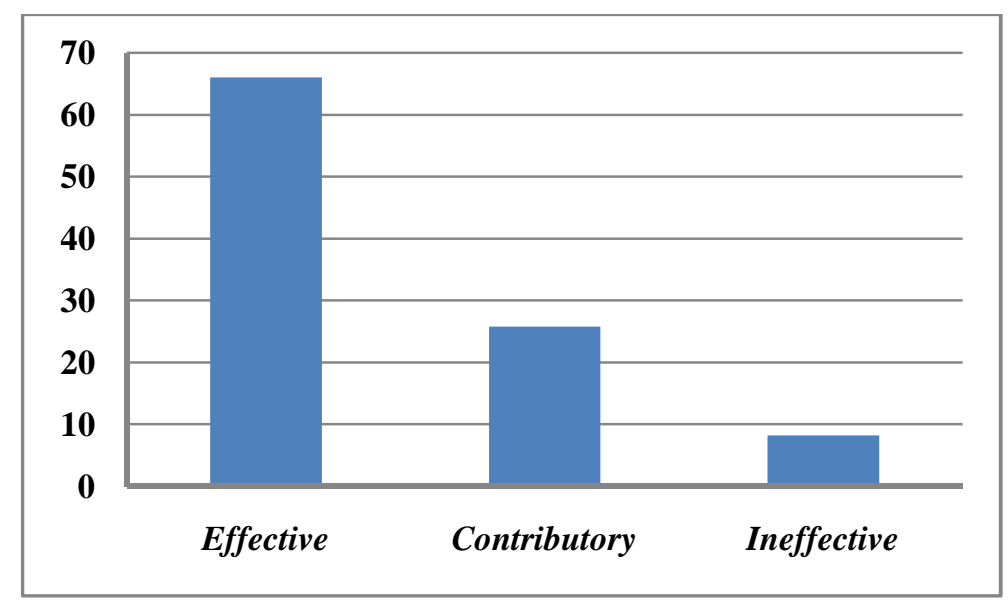

Gambar 1. Hubungan Proporsi dan Jenis Kegiatan

Tabel 2. Berdasarkan Waktu Pengamatan 08.00 - 12.00

\begin{tabular}{lcccc}
\hline \multicolumn{1}{c}{$\begin{array}{c}\text { Jenis } \\
\text { Kegiatan }\end{array}$} & $\begin{array}{c}\text { Jumlah } \\
\text { Pengamatan }\end{array}$ & $\begin{array}{c}\text { Proporsi } \\
(\boldsymbol{\%})\end{array}$ & $\begin{array}{c}\text { Total } \\
(\mathbf{\%})\end{array}$ & $\begin{array}{c}\text { LUR } \\
(\boldsymbol{\%})\end{array}$ \\
\hline Effective & 479 & 65,89 & 65,89 & \\
Essential Contributory & 178 & 24,48 & 90,37 & \\
Ineffective & 70 & 9,63 & 100 & 72,00 \\
Total & 727 & 100 & & \\
\hline
\end{tabular}

Tabel 3. Berdasarkan Waktu Pengamatan 14.00 - 17.00

\begin{tabular}{lcccc}
\hline \multicolumn{1}{c}{$\begin{array}{c}\text { Jenis } \\
\text { Kegiatan }\end{array}$} & $\begin{array}{c}\text { Jumlah } \\
\text { Pengamatan }\end{array}$ & $\begin{array}{c}\text { Proporsi } \\
(\boldsymbol{\%})\end{array}$ & $\begin{array}{c}\text { Total } \\
(\boldsymbol{\%})\end{array}$ & $\begin{array}{c}\text { LUR } \\
(\boldsymbol{\%})\end{array}$ \\
\hline Effective & 362 & 66,06 & 66,06 & \\
Essential Contributory & 149 & 27,19 & 93,25 & \\
Ineffective & 37 & 6,75 & 100 & 72,74 \\
Total & 548 & 100 & & \\
\hline
\end{tabular}

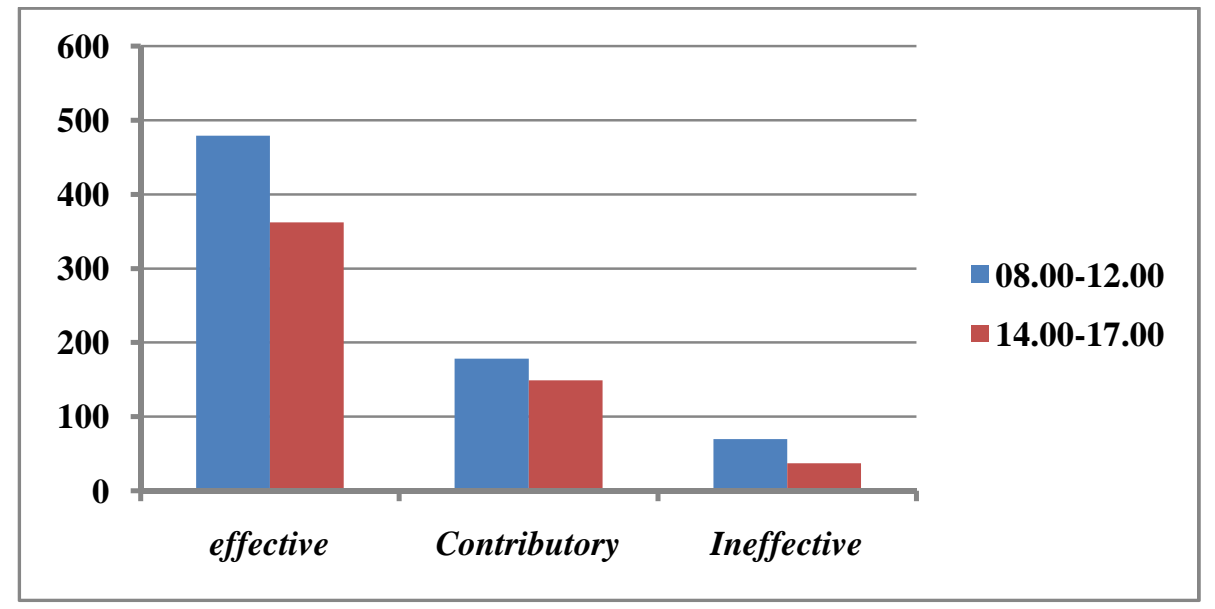

Gambar 2. Hubungan Proporsi dan Jenis Kegiatan Berdasarkan Waktu Pengamatan 


\section{E. KESIMPULAN}

Kesimpulan yang dapat diperoleh dari hasil pengamatan dan analisis adalah bahwa pada Proyek Perumahan di Kota Pekanbaru adalah Nilai Labor Utilization Rate (LUR) sebesar 72,37\% dengan proporsi untuk kegiatan effective $66,03 \%$, essential contributory sebesar $25,79 \%$ dan ineffective sebesar $8,18 \%$

\section{DAFTAR PUSTAKA}

Ching F.D.K., Adams C., 2008, Ilustrasi Konstruksi Bangunan, Erlangga, Jakarta.

Dipohusodo I., 1996, Manajemen Proyek dan Konstruksi, Jilid I Cetakan I, Kanisius, Yogyakarta.

Ervianto W.I., 2005, Teori - Aplikasi Manajemen Proyek Konstruksi, Edisi I, Andi, Yogyakarta.

Ervianto W.I., 2003, Manajemen Proyek Konstruksi, Edisi II, Andi, Yogyakarta.
Hasibuan M., 2003, Organisasi dan Motivasi; Dasar Peningkatan Produktivitas, Cetakan IV, Bumi Aksara, Jakarta.

Husen A., 2011, Manajemen Proyek; Perencanaan, Penjadwalan dan Pengendalian Proyek, Edisi Revisi, Andi, Yogyakarta.

Simanjuntak P.J., 2005, Manajemen dan Evaluasi Kinerja, Lembaga Penerbit Fakultas Ekonomi Universitas Indonesia, Jakarta.

Sinungan M., 2008, Produktivitas; Apa dan Bagaimana, Edisi II Cetakan VII, Bumi Aksara, Jakarta.

Soeharto I., 2001, Manajemen Proyek Dari Konseptual Sampai Operasional, Edisi II Cetakan I, Erlangga, Jakarta.

Sofyandi H., 2008, Manajemen Sumber Daya Manusia, Cetakan 1 Edisi I, Graha Ilmu, Yogyakarta. 